\title{
Adaptation to Climate Change: Opportunities and Challenges from Zambia
}

\author{
Jonty Rawlins and Felix Kanungwe Kalaba
}

\section{Contents}

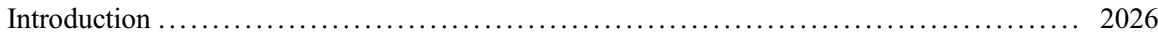

Climate Change in Southern Africa and Zambia ............................ 2028

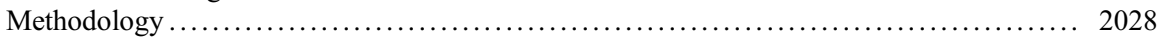

Climate Change Risk Pathways in Zambia ................................... 2029

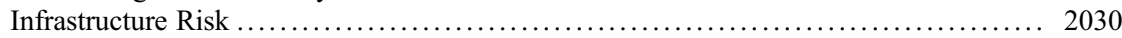

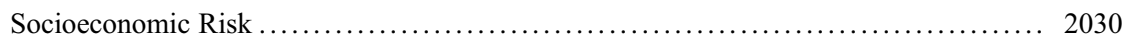

Human Health Risk .................................................. 2031

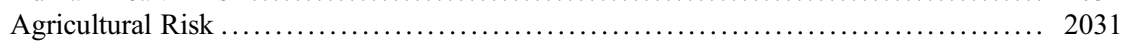

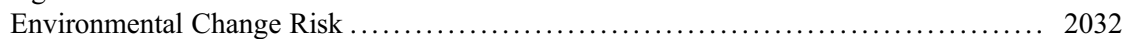

Cumulative Risks and Positive Feedback Loops .............................. 2033

Barriers to Adaptation and Resilience Building ................................ 2033

Poor Livelihood and Economic Diversification ............................. 2033

High Rates of Land Degradation ...................................... 2034

Low Levels of Technical and Technological Capacities ....................... 2034

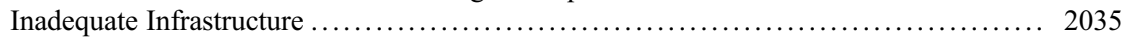

Entrenched Culturally and/or Policy-Driven Practices ........................ 2035

Weak Policy Implementation .......................................... 2035

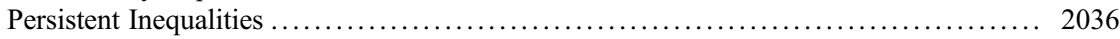

Cumulative Barriers and Positive Feedback Loops ............................ 2036

Toward Improved Climate Change Adaptation ................................. 2037

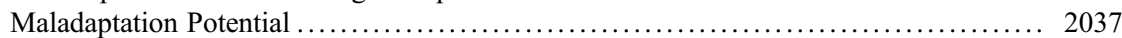

Is Livelihood and Economic Diversification the Answer? ......................... 2038

This chapter was previously published non-open access with exclusive rights reserved by the Publisher. It has been changed retrospectively to open access under a CC BY 4.0 license and the copyright holder is "The Author(s)". For further details, please see the license information at the end of the chapter.

J. Rawlins $(\bowtie)$

Natural Resources, OneWorld Sustainable Investments, Cape Town, South Africa

e-mail: jrawlins@outlook.com

F. K. Kalaba

School of Natural Resources, Copperbelt University, Kitwe, Zambia 


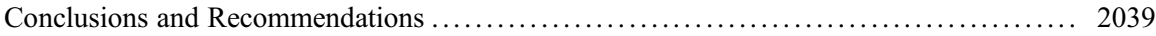

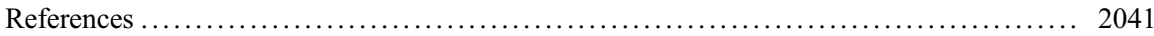

\section{Abstract}

Context appropriate adaptation interventions and strategies that respond directly to localized climate change stressors, hazards, and vulnerabilities are critical for the sustainable development of countries like Zambia. This chapter examines both localized and systemic climate change risk pathways and barriers to adaptation action in Zambia.

A three-staged methodology was applied, combining content analysis, focus group discussions, and expert interviews. Livelihood diversification was identified as the central adaptation option across Zambia, despite little empirical research detailing possible risks of diversification. The dominant adaptation discourse is focused specifically on diversifying within agriculture-based livelihoods. However, as all agricultural activities are impacted by climate change, diversification also needs to be explored in value-added or alternative sectors. With this, a weak policy framework and enabling environment are exacerbating cycles of poverty that underpin climate change vulnerability in Zambia. Moreover, maladaptation risks of existing diversification interventions are high as generic approaches often do not provide suitable options to complex and localized risk profiles.

To implement a sustainable transition toward climate resilient and compatible development in Zambia, the authors recommend that a systematic livelihood diversification strategy should be rolled out and future research programs designed to support this. Specifically, this necessitates a system-wide analysis of pre-identified livelihood diversification pathways that can be adapted to different scenarios given the current and future climate uncertainties at local scales. The approach should focus on harnessing the positive feedback loops for systematic change to build resilience, while minimizing the dominant risk pathways and eliminating persistent barriers that enable positive feedback loops driving vulnerability to climate change. Thorough stakeholder engagement and incremental development of diversification options, incentives, penalties, and other governance and/or policy mechanisms will be needed to support these processes.

\section{Keywords}

Climate change $\cdot$ Adaptation $\cdot$ Sustainable development $\cdot$ Diversification Zambia

\section{Introduction}

There is increasing evidence of the existing and potential impacts of climate change on ecosystems and society (Fischer 2019; Grüneis et al. 2018). These impacts are projected to increase in southern Africa due to projected increases in exposure and existing high levels of sensitivity and low levels of adaptive 
capacity (IPCC 2018). Climate change poses complex challenges to development planning and management at various scales (national, regional, and local) (Whitney and Ban 2019) through a multitude of risk pathways. Globally, enabling effective and efficient adaptation interventions has become a major policy goal over the last decade (Fischer 2019). Recent evidence suggests that adaptation strategies and policies are often developed using a top-down approach (Grüneis et al. 2018). However, there are increasingly urgent calls for locally appropriate adaptation strategies that respond to local scale climate hazards, stressors and vulnerabilities and take cognizance of localized socioeconomic and environmental conditions. Conventional public policy and sustainable development strategies do not effectively incorporate climate change impacts and projections (Whitney and Ban 2019) at a localized scale, often resulting in unintended negative consequences. Designing and implementing effective adaptation actions requires the active participation of local practitioners in order to make decisions on adaptation choices and activities that are locally relevant, credible, and contextually appropriate.

A variety of adaptation measures have been proposed across Africa. However, there is little empirical evidence of how adaptation decisions are contextually developed and to what degree local institutions participate and/or drive such processes. Local institutions understand local contexts and the various climate hazards within their regions and therefore need to be key decision-makers in the development of adaptation strategies and policies (Fischer 2019; Kupika et al. 2019). This is evidenced by extensive scholarship exploring the pervasiveness of maladaptation (e.g., Juhola et al. 2016; Magnan et al. 2016) and issues of scale and applicability of generic adaptation investments under deep uncertainty (Haasnoot et al. 2019; Hallegatte et al. 2012). This is of particular importance in developing adaptation responses to pursue sustainable development outcomes, taking into consideration ecological and social coping and adaptation capacities at multiple spatial scales.

Effective adaptation minimizes negative impacts and maximizes the potential benefits of climate change (Whitney and Ban 2019) given the resource constraints of a particular socio-ecological system. Thus, effective local strategies will, to a large extent, depend on the understanding and perceptions of local actors about opportunities to inform adaptation strategies (Whitney and Ban 2019). Thus, it is clear that pragmatic adaptation actions demand participation of all key local actors and institutions.

This chapter examines the risks from climate change that are currently being experienced and further explores current and future adaptation strategies and barriers to adaptation. Complex and cumulative climate change risk pathways and key barriers to adaptation and resilience building are explored through analyzing perceptions of local actors and institutions within the broader policy and environmental context of Zambia. The overarching objective of this research is to assess and recommend context appropriate and systemic adaptation interventions and strategies that respond directly to both national and localized climate change risks and vulnerabilities. 


\section{Climate Change in Southern Africa and Zambia}

Southern Africa is one of the global climate change hotspots (IPCC 2018). Anthropogenically driven temperature rise is at approximately twice the average global rate of temperature increase (Weber et al. 2018). This is combined with the observed increased frequency and intensity of extreme events such as droughts, heavy rainfall events, heat waves, and floods over the past few decades (Paeth et al. 2010; Taylor et al. 2017). Climate projections for the region also indicate rises in temperatures, an increase in hot days, heat waves, and heat stress as well as continued increases in the frequency and magnitude of extreme events such as droughts and floods (Engelbrecht et al. 2015; Dosio 2017; Maúre et al. 2018).

The severity of these impacts will be magnified by low levels of adaptive capacity, stemming from a plethora of socioeconomic and environmental challenges facing the Southern African region. These factors include rapid population growth, natural resource-related poverty and inequality, regional migration, significant infrastructure deficits, low levels of access to clean water and sanitation, and inefficient food, and energy systems among others (Nhamo et al. 2018; Rawlins et al. 2018).

Zambia is no exception to these trends, with severe climate change impacts projected for the economy, local livelihoods, and the broader environment (Kaluba 2014; World Bank 2019). The country is particularly vulnerable to floods and droughts, which in the past 30 years have cost the country an estimated $13.8 \mathrm{bn}$ USD, equivalent to around $0.4 \%$ of GDP (Kaluba 2014). Zambia has also seen decreased rainfall by an average rate of $1.9 \mathrm{~mm} / \mathrm{month}(2.3 \%)$ per decade since 1960 , and the rainfall season has become shorter and more difficult to predict - with fewer, but more intense rainfall events (AfDB 2019; ZINDC 2015). Mean annual runoff is estimated to decrease by $\sim 13 \%$, under future climate change scenarios (Hamududu and Ngoma 2018). This, combined with increasing climate variability, is reducing water availability across the country. Moreover, vulnerability to climate extremes such as droughts and floods is also increasing, posing a significant threat to water security in the country.

Future scenarios for Zambia over the period 2070-2099 indicate that temperatures will increase by $2{ }^{\circ} \mathrm{C}$ and rainfall could decrease by $8-10 \%$ (Bwalya 2010) with an indication of heavy rainfall events becoming more frequent in the northern highlands (AfDB 2019). As stated above, the frequency of extreme events (droughts, seasonal floods and flash floods, extreme temperatures, and dry spells), along with their intensity and magnitude, has also increased, and is already having notable knock-on effects for local livelihoods.

\section{Methodology}

This chapter adopted a three-staged methodological approach, combining technical content analysis, focus group discussions, and semi-structured expert interviews. In the first stage, we conducted an extensive content analysis of key Zambian national policies that address adaptation to climate change and broader sustainable 
development in one way or another. This included the 2017 National Climate Change Policy, national sectoral policies (water, agriculture, and forestry), and national development plans (Seventh National Development plan and the Vision 2030). Analyzing these policies provided insights on policy direction at the national level and to what degree adaptation to climate change is addressed both implicitly and explicitly as well as the complex interrelations and interdependencies between adaptation and sustainable development objectives.

The second stage involved provincial workshops and a national stakeholder workshop (Lusaka, Zambia, August 2018). Provincial workshops were arranged by district sectoral leads. A total of three provincial level workshops were conducted in Western, Luapula and Northern provinces. These were useful in providing insights into key climate risks being experienced in the various districts of the provinces, and the possible adaptation interventions, which were prioritized by local participants. Participants were drawn from a variety of government departments, NGOs, private sector, and civil society organizations (CSOs). Provincial workshops had an average of 45 participants. We further conducted key informant interviews with provincial heads to understand how localized climate risks in each province related to national, provincial, and local policies and strategies for adaptation and sustainable development. These semi-structured interviews provided the necessary depth in understanding the drivers of and barriers to effective adaptation as well as how these different risks and barriers can interact and accumulate throughout socio-ecological systems. Lastly, we conducted a national workshop, which was attended by 60 experts drawn from across government departments (forestry, agriculture, environment, national development planning, and water), NGOs, and academics.

Finally, semi-structured expert interviews were carried out with experienced academics and practitioners working on a variety of climate change, natural resource, and sustainable development challenges in Zambia and Southern Africa at large. This multistaged approach has been widely used in related studies (e.g., Antwi-Agyei et al. 2018; England et al. 2018). The combination of content analysis, focus group discussions, workshops, and in-depth interviews was shown to be useful in identifying risks, barriers, and possible investments to help adapt to climate change. Specifically, the iterative development of the key findings of the analysis assisted the verification and validation of proposed systemic adaptation responses that will address both national and localized climate change risks in an integrated manner.

\section{Climate Change Risk Pathways in Zambia}

Zambia faces a multitude of climate change risks related to not only the direct effects of climate change but also to infrastructure, social and economic conditions, human health, agriculture, and the natural environment, among others. These risks manifest through a multitude of risk pathways with a variety of impacts over different time horizons that disproportionately impact the most vulnerable 
populations. Additionally, cumulative impacts of these risks regularly lead to positive feedback loops that serve to magnify localized climate change risks.

\section{Infrastructure Risk}

Heavy flooding frequently cuts road access to districts and their administrative centers. Some of the largest contributors to climate sensitivity and vulnerability in Zambia are low road density, the poor quality of many roads, the inability to traverse them for extended periods in the wet season, and the lack of maintenance and "climate proofing" of existing roads (Petrie et al. 2018).

An example of the impact of damage to infrastructure given by workshop participants was that, in remote districts, teachers may not be paid their monthly salaries for months at a time when floods cut road access. Left without an income, they must find the means to obtain food, which they may do by growing food crops themselves. This takes time that they would otherwise use for their teaching load (planning and administrative tasks), which affects the quality of education they deliver. Alternatively, teachers who find this situation difficult may not last more than 2 years in this employment and then leave, resulting in annual staff turnover as high as 30\% (EPDC 2012).

Hydropower accounts for the vast majority of Zambia's energy supplies, with a number of systems currently in operation and a significant amount of planned future generation (e.g., the planned Batoka Gorge Hydropower Plant). The demand for energy is driving continued hydropower development in the region, despite the significant potential decline in hydropower output projected under a drying climate in the Zambezi Basin (Spalding-Fecher et al. 2017). The highly centralized nature and sheer size of the financial investments required to support hydropower infrastructure presents a significant fiscal risk to Zambia given these potential impacts of climate change.

Other examples of the direct and indirect impacts arising from vulnerable road infrastructure are reduced economic activity (trade cannot take place, as markets are inaccessible); and a seasonal lack of access to health and educational facilities. Finally, to compound these factors, authorities are unable to deliver aid when it is needed in times of disaster.

\section{Socioeconomic Risk}

Flooding destroys homes as well as crops and livestock and other household assets. This has an impact on public, household, and individual health and severely affects the access of households to social services. The poor road infrastructure restricts commercial enterprise, depressing local and regional economies and increasing the socioeconomic risks of the region.

A high population growth rate is a key underlying driver of vulnerability, with the rate often exceeding the ability of the economy to absorb job seekers. This highlights the potential future risks to local economies and threatens the ability of social 
services such as education and health facilities to cope with the situation. High levels of education give people more options in terms of diversified livelihoods and income generating activities, while poor access to schooling and poor education or low levels of education hinders adaptation. Without education, people are forced to fall back more strongly on traditional income generation practices. Moreover, risks from the impacts of climate change are exacerbated by the lack of income diversity and high levels of poverty in general.

Gender equality is low in rural areas of Zambia and gender-based violence is common (Samuels et al. 2015). For example, early marriages lead to increased vulnerability of the affected girls. Education levels are low especially for girls who drop out of school to get married. With limited skills, women are restricted in terms of both the value they can add to available natural resources, and the ability to utilize various economic opportunities that would increase the efficiency and productiveness of households to improve their adaptive capacities.

\section{Human Health Risk}

An unhealthy population (or one with a high burden of disease) has a lower resilience to climate change impacts that challenge human health (Smith et al. 2014). HIV/Aids, malaria, and tuberculosis are the most prevalent and therefore serious diseases in Zambia. In addition, the incidence of these diseases reduces the resilience of those individuals and communities affected by other health challenges (i.e., comorbidities).

Poor health infrastructure - inadequate resources, including too few health facilities and staff - is a significant source of vulnerability. This is exacerbated by the remoteness of many districts, and poor roads, meaning that some areas are periodically isolated from health facilities during the wet season, with its concomitant impacts of flooding. It is unclear at this stage how emerging global health risks such as the Corona Virus 2019 (COVID-19) will be influenced by climate change risks; however, it is clear that the potential knock-on effects of a national or global pandemic will further limit the available health infrastructure capacity.

Social issues that result from climate-induced stresses include impacts on mental health. Climate change can affect people directly through trauma, which is evident in climate hazards such as floods. It also affects mental health indirectly, through impacts on physical health and broader community well-being (Berry et al. 2010).

Heat waves and persistent high temperatures will not only alter disease vector habitat distribution (such as malaria and tsetse fly, see Caminade et al. (2014) and Terblanche et al. (2008)), but also pose direct threats to human health in the form of heat stroke, exhaustion, and death.

\section{Agricultural Risk}

Flooding is hazardous to crops across Zambia, though this risk profile varies from region to region. For example, in the higher, steeper areas of districts in Muchinga 
Province, flooding is less of a risk because smaller areas of crops are exposed to the hazard. However, crops along the major rivers can be exposed to prolonged periods of heavy flooding, for example, those in Western Province or parts of Luapula and Northern provinces. With a substantial portion of their food resources for a season destroyed, people must seek alternative forms of income, including relocating for at least part of the agricultural year to other regions in order to generate an income, often by selling labor, charcoal manufacture, or fishing.

The impact of drought on crops and livelihoods varies between the provinces and their districts. In general, mean annual rainfalls are lower in the western and southern regions of Zambia, and droughts are more intense and longer than elsewhere. Droughts in this region have very significant impacts on crop yield. In the northern provinces, where mean annual rainfalls are significantly higher, drought is not a significant risk.

Temperature increases above certain thresholds substantially reduce the grain yield of maize, especially in soils which have a poor water holding capacity (see, e.g., Hatfield and Prueger 2015). This effect is more likely in the western and southern provinces than in the northern provinces, which are at higher altitudes, with higher rainfall and longer growing seasons.

Storm damage to crops - a result of high windspeed during intense events, or hail, is known as a relatively localized event. While devastating for the affected householders, these usually do not occur at district or provincial level. Climate change has shown to have negative effects on livestock leading to reduction in available fodder for animals due to droughts. Floods also affect livestock by reducing the grazing land available, further increasing pressure. Disease incidence for livestock also increased with corresponding increase in animal mortality.

\section{Environmental Change Risk}

Zambia has a burgeoning challenge in deforestation, which has been recognized for some time, in essence since the beginning of the last century (Holden 2001). There are three main causes - land clearing for "slash-and-burn" or Chitimene agriculture, charcoal making, and logging for high-value timber. The earlier land-use changes resulted from population growth and the Chitimene and Fundikila ("grass-mound") farming systems, which required migration and opening up of new areas, especially when cassava and maize-fertilizer systems were implemented in Northern Zambia. These entrenched practices have caused significant environmental changes across the Zambian landscape as well as increased dependence on unsustainable supplies of natural resources, both of which increase vulnerability to climate change.

Fisheries are a critical natural resource in Zambia, but are experiencing overexploitation and are under increasing pressure from external development activities that compromise river ecosystem services and functioning (Cowx et al. 2018). Although there is limited evidence directly linking the decline in inland fisheries in recent years to climate change, there are strong linkages to these declines with overfishing driven by human behavior change (Marshall 2012).

Deforestation and its relationship to climate sensitivity hinges on how changes in vegetation cover affect the physical and chemical components of the environment 
in ways that are likely to reduce resilience to change. Deforestation, followed by agricultural disturbance, results in loss of soil organic carbon and of soil fertility (Chidumayo and Kwibisa 2003). This effect is enhanced by grassland fires (in areas where grass has replaced lost tree cover), with repeated burns also reducing soil carbon. Soil carbon is also important for enhancing soil water retention, an obvious necessity for plant growth and for maintaining growth potential. Deforestation also leads to a decline in soil moisture, which then leads to more surface energy being converted into heat at the land surface. This results in a hotter environment, which at these latitudes is damaging to crop growth and alters pest and disease organism life cycles. Ultimately, deforestation often leads to lower climate resilience.

\section{Cumulative Risks and Positive Feedback Loops}

Infrastructure, socioeconomic, human health, agricultural, and environmental change risks of climate change are not independent of one another and more often than not serve to magnify each other (Mora et al. 2018). These positive feedback loops result in cumulative risk profiles across Zambia, that are deeply entrenched through the existing socio-ecological and economic systems.

Risks of climate change to infrastructure such as road closures and limited access to critical infrastructure serve to exacerbate human health risks because people cannot access hospitals and clinics. Poor health outcomes have knock-on impacts for socioeconomic livelihood activities by reducing the capacity of individuals and households to generate income and/or support social activities within a household. Such risks are closely tied to agriculture as this is the dominant livelihood activity in Zambia; for example, if people cannot work due to poor health or are forced to travel far distances to seek medical care they are often not able to tend to their crops or livestock. This further magnifies the potential risks from climate change to agricultural activities and ultimately agricultural output. Deforestation and over-harvesting of valuable and limited natural resources such as inland fisheries often result from crop failure or livestock die offs, further increasing the risks related to environmental change.

\section{Barriers to Adaptation and Resilience Building}

There are a number of environmental, social, economic, and political barriers to effective climate change adaptation in Zambia. These barriers interact throughout complex socio-ecological systems to reduce adaptive capacities and compound the limits to adaptation throughout the country.

\section{Poor Livelihood and Economic Diversification}

Most rural livelihoods are dependent on natural resources and agriculture. In other words, Zambia has not seen the structural changes in its economy that would enable a permanent shift to one dependent on secondary or tertiary economic activities such 
as manufacturing and services, thus transforming from a natural resource-based economy. This is strongly aligned with broader development imperatives to shift employment from low- to high-productivity sectors.

Local markets and value chains for locally produced goods (especially agricultural products) are underdeveloped. Access to markets is low, primarily due to poor road infrastructure, impacted further by floods and extreme heat, which impact transport time and/or the modality of agricultural produce. Beneficiation processes related to output from key livelihood activities for economic development are highly underdeveloped. Thus, having livelihoods focused on a few highly vulnerable sectors and natural resources serves only to concentrate risks of climate change while simultaneously limiting the ability to adapt. Ultimately, this has resulted in low levels of livelihood and economic diversification both across primary, secondary, and tertiary economic activities as well as within primary production activities themselves.

\section{High Rates of Land Degradation}

Land degradation is primarily driven by unsustainable livelihood practices that are rooted in high levels of poverty and inequality. Harvesting trees for charcoal production and for trade (e.g., for export to China) is adding to already high levels of deforestation. Zambians are often not even the main beneficiaries of revenues from tree-based trade. Mukula (Rosewood), is heavily harvested for timber exports to China. Local cutters receive an average price of about US $\$ 23 /$ cubic meter of timber harvested, while manufacturers in China pay around US $\$ 1,000 /$ cubic meter to importers, before any further processing is done on the exported logs (Cerutti et al. 2018).

Populations are likely to continue to diversify their livelihoods through these and other activities, such as illegal poaching, until there is a proper incentive to secure their livelihoods more sustainably. Together with climate change impacts, these activities are resulting in widespread land degradation and loss of ecosystems, biodiversity, and services that are critical to human welfare and livelihoods, such as water, fisheries, and forests.

\section{Low Levels of Technical and Technological Capacities}

This aspect is evident in very low levels of adoption of new technologies, which range from alternative farming practices, such as conservation agriculture, to capacities to build new climate resilient infrastructure or to retrofit existing infrastructure to be climate resilient. The shift toward decentralization of governance in Zambia raises the challenge of meeting technical capacity needs across the levels of implementation. With this, districts across the studied provinces are limited by lack of the technical capacities needed to drive this implementation. There is thus an evolving trade-off between the necessity to decentralize decision-making power and governance structures with meeting the technical needs for livelihood and economic 
diversification at the local level to adapt to existing and future impacts of climate change.

\section{Inadequate Infrastructure}

Zambia's high levels of infrastructure deficits in transport, energy, Information and Communications Technology (ICT), and water and sanitation significantly impede adaptive capacities. Notably, business productivity is severely hampered by the infrastructure deficits. This reduces investments in commercial activities and limits expansion of smaller businesses, further limiting income diversification opportunities. Furthermore, $50 \%$ of the productivity gap in Zambia is attributed by firms to the state of the country's infrastructure (Foster and Dominguez 2011). Most of the productivity gap is attributed to power, followed by transport and ICT. As mentioned above, road infrastructure is insufficient and plays a pivotal role for all forms of infrastructure.

\section{Entrenched Culturally and/or Policy-Driven Practices}

Zambians are often forced to default to livelihoods and coping strategies that are supported by long-standing traditional beliefs, which are in some instances supported by well-entrenched policies. For example, high cultural value is placed on cattle ownership, to the extent that farmers often refuse to sell them off during extreme droughts, in the hopes they will survive and regain health, even though the farmers cannot feed and water them. Often the cattle do not survive.

Policies can also entrench practices not conducive to climate change. For example, policy-driven maize production has increased farmer dependence on a vulnerable livelihood and its status as the country's most desired food staple (Chapoto et al. 2010). Problematically, maize is not a drought-resilient crop and yields in Zambia are quite low, also partly due to the policy emphasis on production rather than productivity (Petrie et al. 2014). Consequently, farmers are not diversifying their risks by growing additional or alternate crops, which may be more drought resilient. Nor are they considering alternate livelihoods because the culturally and policydriven practice of maize farming is so entrenched.

\section{Weak Policy Implementation}

Supportive policy frameworks that enable adaptation are relatively well established in Zambia. For example, the 2017 National Climate Change Policy details a broad approach to strengthen the implementation of adaptation measures to reduce vulnerability to climate change, which supports and builds on the objectives outlined in the 7th National Development Plan. However, these policies are generally not effectively applied or fully implemented due to a number of related barriers, such 
as breadth of technical capacity, conflicting discourse on development objectives, lack of financing opportunities, and weak institutional arrangements (Romdhani et al. 2018). This is particularly true in rural areas, where institutional arrangements and related enforcement mechanisms are relatively weak and government institutions are poorly capacitated; yet people in these areas are the most vulnerable to the impacts of climate change.

\section{Persistent Inequalities}

Gender inequality and gender-based violence persists despite transversal policy. Women lack access to land in comparison to men, under customary law that disadvantages women in terms of land allocation. This compromises agricultural productivity and food security, particularly in situations where women have the responsibility over daily household welfare without decision-making powers over land and land use, and in the face of little access to disposable income. With this, female farmers tend to have even lower access than men to agricultural inputs.

Even if there were greater opportunities for livelihoods and incomes beyond natural resource-based sectors, education, a key indicator of adaptive capacity, is low in the studied provinces. This limits people's access to opportunities, particularly affecting women. Inequalities are also highly evident in access to safe water, electricity, and public health services, which tends to be much lower in rural areas making people less able to adapt to the impacts of climate change. Ultimately, this reduces the adaptive capacity of these individuals and communities and reduces their opportunities to diversify.

\section{Cumulative Barriers and Positive Feedback Loops}

Similar to the cumulative nature of the climate change risk pathways, the abovementioned barriers to adaptation can also create positive feedback loops that serve to reinforce these barriers and ultimately limit resilience building opportunities (Shackleton et al. 2015). A key example from the Zambian context relates to both weak policy implementation and the myopic culturally entrenched and policy-driven practices. Agriculture-based livelihoods being culturally entrenched and together driven by centralized blanket maize cultivation incentives create more significant barriers to effective adaptation when combined with poor implementation of climate change policies. Moreover, traditional livelihoods serve to reinforce the status quo around traditional gender roles and thus further entrench the persistent inequalities. Moreover, traditional livelihood practices and high levels of inequality and poverty drive unsustainable land-use practices and ultimately lead to degradation. This phenomenon is heightened due to the increasing nature of crop failures and livestock die offs due to the impacts of climate change.

Given that low population densities and high travel distances necessitate greater per capita investment for infrastructure construction (Chapman et al. 2013), the 
widespread nature of rural and subsistence-based livelihoods across the country compound the difficulty of infrastructure provision. The same logic applies to the adoption of novel technologies and livelihood practices as well as the opportunities to access alternative markets and economies.

\section{Toward Improved Climate Change Adaptation}

Climate change risk pathways and barriers to adaptation manifest through a complex network of social, economic, and environmental feedback loops, often resulting in positive feedback loops that intensify the initial perceived risk of a particular climate hazard or stressor. These potentially antagonistic relationships between different risk pathways and socioeconomic barriers to adaptation highlight the complexity of the interdependent nature of socio-ecological systems in Zambia. The benefits of developing adaptation responses that focus on individual climate change risk pathways or barriers will be abated due to the complex synergistic and antagonistic feedback loops that characterize these systems. Thus, these complex interactions highlight the need for systematic responses to minimize risks and overcome the barriers.

In Zambia, the complex and emergent properties of the socio-ecological systems, combined with their strong dependency on climate systems, elucidate the intrinsic and inextricable relationship between climate change and sustainable development. Thus, effective adaptation responses need to take a systematic approach that attempts to address the myriad of complex climate change risks concurrently with existing barriers to adaptation. Kim et al. (2018) show that community social and ecological climate change risk characteristics were reduced by higher levels of social capital combined with local proactive planning and policy measures focused on systematic responses to cumulative exposure. The notion of an integrated and systematic response to stressors and shocks on socio-ecological systems and related economic activities is widely considered effective, whether or not these external stressors and shocks are related to climate change or not (Cinner and Barnes 2019; Fedele et al. 2019; Hafezi et al. 2018).

\section{Maladaptation Potential}

Responding to a myriad of climate change threats across Zambia requires both increased resilience to short- to medium-term shocks (e.g., floods and droughts) combined with sustained and more gradual adaptation to climate change (temperature rise and seasonal rainfall changes) across systems and society. Moreover, this necessitates rigorous assessments of maladaptation potential for proposed interventions. Much of the onus for this falls on government institutions and the Zambian governance framework because the role of the developmental state is to balance social development with economic growth in a sustainable manner. However, maladaptation risks are high and generic approaches to diversifying livelihoods do 
not always provide the best options to complex risk profiles associated with poverty, climate change, and environmental degradation.

Maladaptive actions may lead to increased risks of adverse climate-related outcomes (IPCC 2018). Thus, understanding the potential for maladaptation is critical for planning and budgeting for adaptation interventions. Zambia faces enormous opportunities to improve livelihoods and living standards through adaptation; however, the significant scope of the opportunity raises the likelihood of maladaptive outcomes.

Improving road infrastructure, for example, has its own risks, despite the notable potential for positive sustainable development and climate change adaptation outcomes. In many parts of Zambia, such as Western Province, illegal tree harvesting of species such as Mzauli (African rosewood - Guibourtia coleosperma) is taking place, with the timber being exported through Namibia. This is leading to a decline in this species. Improved roads into these areas could facilitate increased penetration of illegal tree fellers.

\section{Is Livelihood and Economic Diversification the Answer?}

Livelihood and economic diversification are regularly identified as a key adaptation option given the current socioeconomic state of Zambian populations and communities and the current and projected impacts of climate change (Petrie et al. 2018). The dominant discourse around adaptation in Zambia is focused on agriculturebased livelihoods, which are facing the greatest risks from climate change. Currently, in response, adaptation interventions are focused on transitions to (and between) different forms of conservation agriculture, crop diversification, and a combination of farm and nonfarm activities such as seasonal fishing and charcoal production (Loison 2015; Romdhani et al. 2018).

Zambia's favorable agro-climatic conditions are suitable for producing a diverse variety of livestock and crops; however, legacy blanket policies promoting the cultivation and consumption of maize have limited these opportunities significantly. In $2015, \pm 98 \%$ of smallholder households were cultivating maize, while it is estimated that more than half of the land under crop production in Zambia is devoted to maize (CSO 2015). Moreover, Mofya-Mukuka and Hichaambwa (2018) found that government input subsidies and direct market support for maize have negatively affected crop diversification by rural households. Additionally, compared to neighboring countries in the region, Zambia's level of crop diversification is low (as measured by the Simpson Index of Diversification $= \pm 0.37$ ) (World Bank 2018). Despite this the potential for diversification has been shown to be good. Alfani et al. (2019) found in Zambia that general diversification actions such as livestock and income diversification and the adoption of agro-forestry as an alternative economic activity served to moderate the impact of a recent severe drought. Interestingly, it was also found that some agro-ecological practices such as minimum soil disturbance was not effective in moderating any yield and income effects of the drought. Additionally, Wineman and Crawford (2017) demonstrate that given the current set 
of available diversification options, autonomous on-farm adaptation will not be sufficient to offset the negative yield effects of climate change.

Combined with the notable vulnerability of maize production to projected climate change in Zambia (Wineman and Crawford 2017; Petrie et al. 2014), the rationale for diversification to improve income and/or food security is clear. However, the perceived benefits of diversification might not always materialize on the ground, as the enabling environment to support such diversification is weak. Loison (2015) emphasizes that it is only the relatively better-off smallholders with sufficient assets who achieve successful livelihood diversification; and thus, associated increases in income and wealth based on livelihood diversification are yet to show notable benefits for smallholder farmers that are implementing diversified livelihood activities. The same argument holds in relation to improving climate resilience through livelihood diversification. Climate change vulnerability in Zambia is largely a function of people's poor ability to adapt (i.e., adaptive capacity), which is driven by high levels of poverty and a lack of access to basic services and supporting infrastructure (Petrie et al. 2018).

Despite multiple proponents of diversification as a key strategy for climate-smart agriculture in Zambia (Arslan et al. 2018), there is little empirical research detailing the possible risks of diversification. Moreover, risks of promoting diversification are exacerbated by the weak enabling environment. For example, diversifying agricultural practices requires knowledge, skills, and inputs to grow multiple types of crops and/or rear multiple different types of livestock. Not only could this cost more in the short run; there is also a greater risk of making mistakes. Diversification can also lead to localized competition for markets, leading to possible conflicts. Importantly, promoting over-diversified livelihood activities might limit opportunities to upscale by taking advantage of economies of scale through access more well developed markets and value chains. These risks might exacerbate the cycles of poverty that underpin climate change vulnerability in Zambia.

It is clear that livelihood diversification presents significant opportunities and challenges, which means it should not be viewed as an adaptation panacea in low income settings. People will naturally adapt and diversify, where livelihood and/or income opportunities are better. Hence there is a clear need for dedicated policy and governance efforts to systematically target, support, and incentivize context-specific livelihood diversification opportunities that are harmonized across competing developmental objectives. Bhatta et al. (2015) highlight that livelihood and diversification strategies need to be tailored to both localized climatic and non-climatic resources alike to minimize risks and facilitate the lowest-cost (social and economic) transition to climate resilience.

\section{Conclusions and Recommendations}

The system- and society-wide impacts of climate change in Zambia require transformational change in sustainable development. Zambia's dependence, for example, on agriculture for its economy and for livelihoods, places the country and its 
populations at high risk to climate change. The related national policies, such as the incentivization of maize production, do not capture the localized livelihood contexts and climate risk profiles. The link between climate change and sustainable development in Zambia is inextricable, however, and thus these two concepts should not be viewed in isolation from one another.

Livelihood diversification was identified as the central adaptation option across Zambia, despite little empirical research detailing possible risks of diversification. The dominant adaptation discourse is focused specifically on diversifying within agriculture-based livelihoods. However, as all agricultural activities are impacted by climate change, diversification also needs to be explored in value added or alternative sectors. With this, a weak policy framework and enabling environment is exacerbating cycles of poverty that underpin climate change vulnerability in Zambia. Moreover, maladaptation risks of existing diversification interventions are high as generic approaches often do not provide suitable options to complex and localized risk profiles.

It is evident that there is a strong need to diversify both within and outside of the agriculture sector, but how this is done will be critical. Thus, the authors recommend the development of a detailed spatial assessment of the economic, environmental, and social complexities that contribute to differing levels of climate change vulnerability throughout Zambia and how these contribute to or detract from realizing national sustainable development objectives. Specifically, there is a need to focus on harnessing the positive feedback loops for systematic change to build resilience, while minimizing the dominant risk pathways and eliminating persistent barriers that enable positive feedback loops driving vulnerability to climate change.

First, this will necessitate a detailed examination of a selected range of pathways for alternate crops, livestock farming, fisheries exploitation, and secondary and tertiary services to understand key elements ranging from production to market economics across the various value chains. In this way it will be possible to establish which livelihoods are most appropriate for different areas, and how these might be influenced by projected changes in climate. It will also be important to ascertain how these can best be initiated and sustained from initial development onward in a way that aligns with national development objectives and policy priorities. Potential maladaptation risks of diversification can be addressed through continued stakeholder engagement and incremental development of diversification incentives, penalties, and other governance and/or policy support mechanisms.

To ensure a sustainable transition toward climate resilient and compatible development in Zambia, this systematic approach toward facilitating diversification throughout the economy should be supported by complementary approaches toward land-use and natural resources management, urban planning and infrastructure development. Future research endeavors in the region should focus on supporting this type of holistic approach by developing the evidence-base for change. Specifically, there is a need for a greater understanding of the complex interactions and emergent properties of socio-ecological systems in low-income settings that can inform policy direction at the local scale. This applies specifically to the derivation and classification of combined climate change and developmental 
risks, how these accumulate in a system and how best these can be addressed given existing resource constraints.

Additionally, future research should also focus on developing innovative densified development models in low-income settings, which can balance the need to simultaneously realize social, economic, and environmental development imperatives. Particular emphasis should be given to the potential role of nature-based solutions and the integration of ecological and traditional gray infrastructure. Ultimately, this approach toward evidence-led policy implementation will assist to minimize risks of upscaling livelihood and economic diversification actions, while continuing to facilitate an effective transition toward climate resilience through planned and incremental change.

\section{References}

AfDB (2019) National climate change profile: zambia. Available: https://www.afdb.org/en/docu ments/zambia-national-climate-change-profile

Alfani F, Arslan A, McCarthy N, Cavatassi R, Sitko N (2019) Climate-change vulnerability in rural Zambia: the impact of an El Niño-induced shock on income and productivity. FAO agricultural development economics working paper 19-02. FAO, Rome, p 41

Antwi-Agyei P, Dougill A, Agyekum T, Stringer L (2018) Alignment between nationally determined contributions and the sustainable development goals for West Africa. Clim Pol 18:1-17. https://doi.org/10.1080/14693062.2018.1431199

Arslan A, Cavatassi R, Alfani F, Mccarthy N, Lipper L, Kokwe M (2018) Diversification under climate variability as part of a CSA strategy in rural Zambia. J Dev Stud 54:457-480. https://doi. org $/ 10.1080 / 00220388.2017 .1293813$

Berry HL, Bowen K, Kjellstrom T (2010) Climate change and mental health: a causal pathways framework. Int J Public Health 55(2):123-132

Bhatta GD, Aggarwal PK, Shrivastava A (2015) Livelihood diversification and climate change adaptation in Indo-Gangetic plains: implication of rainfall regimes. J Agric Environ 16:77-94. https://doi.org/10.3126/aej.v16i0.19841

Bwalya SM (2010) Climate change in Zambia: opportunities for adaptation and mitigation through Africa bio-carbon initiative. Center for International Forest Research Southern Africa, Lusaka

Caminade C, Kovats S, Rocklov J, Tompkins AM, Morse AP, Colón-González FJ, Stenlund H, Martens P, Lloyd SJ (2014) Impact of climate change on global malaria distribution. PNAS 111:3286-3291. https://doi.org/10.1073/pnas.1302089111

Cerutti PO, Gumbo D, Moombe K, Schoneveld G, Nasi R, Bourland N, Weng X (2018) Informality, global capital, rural development and the environment: Mukula (rosewood) trade between China and Zambia. Research report. IIED/CIFOR, London/Lusaka

Chapman L, Azevedo JA, Prieto-Lopez T (2013) Urban heat \& critical infrastructure networks: a viewpoint. Urban Clim 3:7-12. https://doi.org/10.1016/j.uclim.2013.04.001

Chapoto A, Govereh J, Haggblade S, Jayne TS (2010) Staple food prices in Zambia. Food Security Collaborative working papers 58556. Michigan State University, Department of Agricultural, Food, and Resource Economics

Chidumayo EN, Kwibisa L (2003) Effects of deforestation on grass biomass and soil nutrient status in miombo woodland, Zambia. Agric Ecosyst Environ 96:97-105. https://doi.org/10.1016/ S0167-8809(02)00229-3

Cinner JE, Barnes ML (2019) Social dimensions of resilience in social-ecological systems. One Earth 1:51-56. https://doi.org/10.1016/j.oneear.2019.08.003 
Cowx IG, Lungu A, Kalonga M (2018) Optimising hydropower development and ecosystem services in the Kafue River, Zambia. Mar Freshw Res 69:1974-1982. https://doi.org/10.1071/ MF18132

CSO (2015) Rural Agricultural Livelihood Survey (RALS). Central Statistical Office, Ministry of Agriculture and Cooperatives and Indaba Agricultural Policy Research Institute. CSO, MAL, IAPRI, Lusaka

Dosio A (2017) Projection of temperature and heat waves for Africa with an ensemble of CORDEX Regional Climate Models. Clim Dyn 49(1):493-519. https://doi.org/10.1007/s00382-016-33555

Engelbrecht F, Adegoke J, Bopape MJ, Naidoo M, Garland R, Thatcher M, McGregor J, Katzfey J, Werner M, Ichoku C, Gatebe C (2015) Projections of rapidly rising surface temperatures over Africa under low mitigation. Environ Res Lett 10:085004. https://doi.org/10.1088/1748-9326/ $10 / 8 / 085004$

England MI, Dougill AJ, Stringer LC, Vincent KE, Pardoe J, Kalaba FK, Mkwambisi DD, Namaganda E, Afionis S (2018) Climate change adaptation and cross-sectoral policy coherence in southern Africa. Reg Environ Change 18:2059-2071. https://doi.org/10.1007/s10113-018$1283-0$

EPDC (2012) Zambia - making sense of data to improve education for development. Education Policy Data Center. https://www.epdc.org/country/zambia

Fedele G, Donatti CI, Harvey CA, Hannah L, Hole DG (2019) Transformative adaptation to climate change for sustainable social-ecological systems. Environ Sci Pol 101:116-125. https://doi.org/ 10.1016/j.envsci.2019.07.001

Fischer AP (2019) Adapting and coping with climate change in temperate forests. Glob Environ Chang. https://doi.org/10.1016/j.gloenvcha.2018.10.011

Foster V, Dominguez C (2011) Zambia's infrastructure: a continental perspective. The World Bank policy research working paper 5599. The World Bank, Washington, DC

Grüneis H, Penker M, Höferl KM, Schermer M, Scherhaufer P (2018) Why do we not pick the lowhanging fruit? Governing adaptation to climate change and resilience in Tyrolean mountain agriculture. Land Use Policy 79:386-396

Haasnoot M, van Aalst M, Rozenberg J, Dominique K, Matthews J, Bouwer LM, Kind J, Poff NL (2019) Investments under non-stationarity: economic evaluation of adaptation pathways. Clim Chang 161:1-13

Hafezi M, Sahin O, Stewart RA, Mackey B (2018) Creating a novel multi-layered integrative climate change adaptation planning approach using a systematic literature review. Sustainability 10:4100. https://doi.org/10.3390/su10114100

Hallegatte S, Shah A, Lempert R, Brown C, Gill S (2012) Investment decision making under deep uncertainty-application to climate change. The World Bank, Washington, DC

Hamududu B, Ngoma H (2018) Impacts of climate change on water availability in Zambia: implications for irrigation development. Technical paper number 7. Indaba Agricultural Policy Research Institute (IAPRI), Lusaka

Hatfield JL, Prueger JH (2015) Temperature extremes: effect on plant growth and development. USDA Research and Programs Extreme Events. Weather Clim Extremes 10:4-10. https://doi. org/10.1016/j.wace.2015.08.001

Holden S (2001) A century of technological change and deforestation in the miombo woodlands of Northern Zambia. In: Angelsen A, Kaimowitz D (eds) Agricultural technologies and tropical deforestation. CABI, New York, pp 251-270

IPCC (2018) Global warming of $1.5^{\circ} \mathrm{C}$ : an IPCC special report on the impacts of global warming of $1.5^{\circ} \mathrm{C}$ above pre-industrial levels and related global greenhouse gas emission pathways, in the context of strengthening the global response to the threat of climate change, sustainable development, and efforts to eradicate poverty. Intergovernmental Panel on Climate Change, Geneva

Juhola S, Glaas E, Linnér BO, Neset TS (2016) Redefining maladaptation. Environ Sci Pol $55: 135-140$ 
Kaluba D (2014) Republic of Zambia pilot program for climate resilience: climate resilience and economic development. http://www.oecd.org/env/cc/Session\%204\%20-\%20Kaluba\%20Cli mate\%20Resilience\%20and\%20Economic\%20Growth.pdf

Kim H, Marcouiller DW, Woosnam KM (2018) Rescaling social dynamics in climate change: the implications of cumulative exposure, climate justice, and community resilience. Geoforum 96:129-140. https://doi.org/10.1016/j.geoforum.2018.08.006

Kupika LO et al (2019) Local ecological knowledge on climate change and ecosystem-based adaptation strategies promote resilience in the Middle Zambezi Biosphere Reserve, Zimbabwe. Wildlife conservation in tropical savanna ecosystem. Scientifica 2019:3069254. https://doi.org/ $10.1155 / 2019 / 3069254$

Loison SA (2015) Rural livelihood diversification in sub-Saharan Africa: a literature review. J Dev Stud 51:1125-1138. https://doi.org/10.1080/00220388.2015.1046445

Magnan AK, Schipper E, Burkett M, Bharwani S, Burton I, Eriksen S, Gemenne F, Schaar J, Ziervogel G (2016) Addressing the risk of maladaptation to climate change. WIREs Clim Change 7:646-665. https://doi.org/10.1002/wcc.409

Marshall BE (2012) Does climate change really explain changes in the fisheries productivity of Lake Kariba (Zambia-Zimbabwe)? Trans R Soc S Afr 67:45-51. https://doi.org/10.1080/ 0035919X.2012.694083

Maúre $\mathrm{G}$ et al (2018) The southern African climate under $1.5^{\circ} \mathrm{C}$ and $2{ }^{\circ} \mathrm{C}$ of global warming as simulated by CORDEX regional climate models. Environ Res Lett 13(6):065002. https://doi. org/10.1088/1748-9326/aab190

Mofya-Mukuka R, Hichaambwa M (2018) Livelihood effects of crop diversification: a panel data analysis of rural farm households in Zambia. Food Sec 10:1449-1462

Mora C, Spirandelli D, Franklin EC, Lynham J, Kantar MB, Miles W, Smith CZ, Freel K, Moy J, Louis LV, Barba EW, Bettinger K, Frazier AG, Colburn Ix JF, Hanasaki N, Hawkins E, Hirabayashi Y, Knorr W, Little CM, Emanuel K, Sheffield J, Patz JA, Hunter CL (2018) Broad threat to humanity from cumulative climate hazards intensified by greenhouse gas emissions. Nat Clim Chang 8:1062-1071. https://doi.org/10.1038/s41558-018-0315-6

Nhamo L, Ndlela B, Nhemachena C, Mabhaudhi T, Mpandeli S, Matchaya G (2018) The waterenergy-food nexus: climate risks and opportunities in southern Africa. Water 10(5):567. https:// doi.org/10.3390/w10050567

Paeth $\mathrm{H}$ et al (2010) Meteorological characteristics and potential causes of the 2007 flood in subSaharan Africa. Int J Climatol 31(13):1908-1926. https://doi.org/10.1002/joc.2199

Petrie B, Chapman A, Midgley A, Parker R (2014) Risk, vulnerability and resilience in the Limpopo River Basin system: climate change, water and biodiversity - a synthesis. For the RESILIM Program, USAID. OneWorld Sustainable Investments, Cape Town

Petrie B, Rawlins J, Perkins D, Lumbroso D, Chapman A (2018) Climate change risk and vulnerability assessment in Luapula, Muchinga, Northern and Western Provinces of Zambia. OneWorld Sustainable Investments, Cape Town

Rawlins J, Petrie B, Gerhard M, Filipova A (2018) Towards cooperative transboundary environmental management in SADC: politics and harmonisation. Political drivers for sustainable ecosystems: building peace. World Water Week, August 2018, Stockholm

Romdhani A, Coll Besa M, Scott D, Bharwani S (2018) Zambia's adaptation to climate change. Stockholm Environment Institute, Stockholm

Samuels F, Ndubani P, Walker D, Simbaya J (2015) Baseline study: Stamping Out and Preventing Gender Based Violence (STOP GBV) in Zambia. ODI Frontiers Research Group, ODI, Blackfriars

Shackleton S, Ziervogel G, Sallu S, Gil T, Tschakert P (2015) Why is socially-just climate change adaptation in sub-Saharan Africa so challenging? A review of barriers identified from empirical cases. WIREs Clim Change 6:321-344. https://doi.org/10.1002/wcc.335

Smith KR, Woodward A, Campbell-Lendrum D, Chadee DD, Honda Y, Liu Q, Olwoch JM, Revich B, Sauerborn R (2014) Human health: impacts, adaptation, and co-benefits. In: Field CB, Barros VR, Dokken DJ, Mach KJ, Mastrandrea MD, Bilir TE, Chatterjee M, Ebi KL, Estrada YO, 
Genova RC, Girma B, Kissel ES, Levy AN, MacCracken S, Mastrandrea PR, White LL (eds) Climate change 2014: impacts, adaptation, and vulnerability. Part A: global and sectoral aspects. Contribution of working group II to the fifth assessment report of the Intergovernmental Panel on Climate Change. Cambridge University Press, Cambridge, UK/New York, pp 709-754

Spalding-Fecher R, Joyce B, Winkler H (2017) Climate change and hydropower in the Southern African Power Pool and Zambezi River Basin: system-wide impacts and policy implications. Energy Policy 103:84-97. https://doi.org/10.1016/j.enpol.2016.12.009

Taylor CM et al (2017) Frequency of extreme Sahelian storms tripled since 1982 in satellite observations. Nature 544(7651):475-478. https://doi.org/10.1038/nature22069

Terblanche JS, Clusella-Trullas S, Deere JA, Chown SL (2008) Thermal tolerance in a south-east African population of the tsetse fly Glossina pallidipes (Diptera, Glossinidae): implications for forecasting climate change impacts. J Insect Physiol 54:114-127. https://doi.org/10.1016/j. jinsphys.2007.08.007

Weber T et al (2018) Analysing regional climate change in Africa in a $1.5^{\circ} \mathrm{C}, 2{ }^{\circ} \mathrm{C}$ and $3{ }^{\circ} \mathrm{C}$ global warming world. Earth's Future 6:1-13. https://doi.org/10.1002/2017ef000714

Whitney CK, Ban NC (2019) Barriers and opportunities for social-ecological adaptation to climate change in coastal British Columbia. Ocean Coast Manag 179:104808

Wineman A, Crawford EW (2017) Climate change and crop choice in Zambia: a mathematical programming approach. NJAS Wagening J Life Sci 81:19-31. https://doi.org/10.1016/j. njas.2017.02.002

World Bank (2018) Productive diversification of African agriculture and its effects on resilience and nutrition. World Bank, Washington, DC

World Bank (2019) Climate change knowledge portal: zambia. Available: https://climateknowl edgeportal.worldbank.org/country/zambia

ZINDC (2015) Zambia's Intended Nationally Determined Contribution (INDC) to the 2015 Agreement on Climate Change. Available: http://www4.unfccc.int

Open Access This chapter is licensed under the terms of the Creative Commons Attribution 4.0 International License (http://creativecommons.org/licenses/by/4.0/), which permits use, sharing, adaptation, distribution and reproduction in any medium or format, as long as you give appropriate credit to the original author(s) and the source, provide a link to the Creative Commons license and indicate if changes were made.

The images or other third party material in this chapter are included in the chapter's Creative Commons license, unless indicated otherwise in a credit line to the material. If material is not included in the chapter's Creative Commons license and your intended use is not permitted by statutory regulation or exceeds the permitted use, you will need to obtain permission directly from the copyright holder.

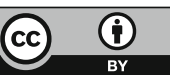

